\title{
The qualitative research proposal
}

\author{
H Klopper, PhD; MBA \\ Professor, School of Nursing Science, North-West University (Potchefstroom Campus), South Africa
}

Key words: Proposal, Qualitative Research, Attributes, Qualitative Process

\begin{abstract}
Curationis 31(4): $62-72$
Qualitative research in the health sciences has had to overcome many prejudices and a number of misunderstandings, but today qualitative research is as acceptable as quantitative research designs and is widely funded and published. Writing the proposal of a qualitative study, however, can be a challenging feat, due to the emergent nature of the qualitative research design and the description of the methodology as a process. Even today, many sub-standard proposals at post-graduate evaluation committees and application proposals to be considered for funding are still seen. This problem has led the researcher to develop a framework to guide the qualitative researcher in writing the proposal of a qualitative study based on the following research questions: (i) What is the process of writing a qualitative research proposal? and (ii) What does the structure and layout of a qualitative proposal look like? The purpose of this article is to discuss the process of writing the qualitative research proposal, as well as describe the structure and layout of a qualitative research proposal. The process of writing a qualitative research proposal is discussed with regards to the most important questions that need to be answered in your research proposal with consideration of the guidelines of being practical, being persuasive, making broader links, aiming for crystal clarity and planning before you write. While the structure of the qualitative research proposal is discussed with regards to the key sections of the proposal, namely the cover page, abstract, introduction, review of the literature, research problem and research questions, research purpose and objectives, research paradigm, research design, research method, ethical considerations, dissemination plan, budget and appendices.
\end{abstract}

\section{Background and introduction}

Morse (2003:833) points out that qualitative methodology is used when little is known about a topic, the research context is poorly understood, the boundaries of a domain are illdefined, the phenomenon under investigation is not quantifiable, the nature of the problem is not clear, or the researcher suspects that the phenomenon needs to be re-examined. Researchers need a clear picture of the issues and questions that they want to investigate, as well as ideas of how they are going to go about investigating them, but always with an openness of mind to improvise, revise and adjust. Writing a proposal for a qualitative study is therefore a challenge, as the qualitative researcher "designs studies by conducting them - as opposed to conducting studies by design" (Sandelowski \& Barroso, 2003:781). Quantitative researchers generally believe they know what they do not know (i.e. knowing the type of knowledge they expect to obtain by doing a study and then striving to obtain it). A qualitative researcher, by contrast, enters the study "not knowing what is known" (i.e. not knowing the phenomenon that will drive the inquiry forward) (Loiselle, Profetto-McGrath, Polit \& Beck, 2004:208). The qualitative proposal writer can therefore only anticipate how the study will proceed. Qualitative research begins by accepting that there 
is a range of different ways of making sense of the world (that the truth is only valid in a specific context) and is concerned with discovering the meanings seen by those who are being researched and with understanding their view of the world rather than that of the researcher (Jones, 1995:2)

\section{Problem statement}

Qualitative research in the health sciences has had to overcome prejudice and a number of misunderstandings. Some of the misunderstandings include the beliefs that qualitative research is "easy"; and the "stigma of the small sample". However, by now we know that qualitative research experts make these misinterpretations redundant and irrelevant as more and more qualitative studies are funded, and results are published widely. Notwithstanding the fact that qualitative research is now as acceptable as quantitative research designs, sub-standard proposals at post-graduate evaluation committees or application proposals to be considered for funding are still seen. Writing the proposal of a qualitative study is challenging due to the emergent nature of the qualitative research design and the description of the methodology as a process. In response to the nature of health care practices that focus on patient care, there is an increased tendency to investigate phenomena from a qualitative perspective. Therefore the following questions can be asked: (i) What is the process of writing a qualitative research proposal? and (ii) What does the structure and layout of a qualitative proposal look like?

\section{Purpose}

The purpose of this article is twofold, i.e. the process of writing the qualitative research proposal will be discussed, followed by a description of the structure of a qualitative research proposal, including examples from qualitative studies (where relevant).

\section{Process of the qualitative proposal}

Qualitative researchers often find themselves in a "catch-22" situation. They have intentionally selected a qualitative research design, as little is known about the phenomenon to be studied: yet it is expected to write how data analysis will be done when the data is not known. However, it is imperative that the researcher must convince the proposal evaluation committee or funding agency reviewers in order to be allowed to proceed with the study. In response to this situation, Morse and Field (1996:35) remark that "clearly, developing a rigid plan for a qualitative project, including detailed plans for data collection and analysis, becomes impossible when writing qualitative proposals". Unlike positivist research, there is no single accepted framework for a qualitative research proposal. To present an acceptable proposal means shifting away from one's own concerns and thinking about the questions that the reader(s) or reviewer(s) of the research proposal will be asking (Silverman, 2000:113). These questions do not necessarily differ from the questions asked in quantitative research, but will alert one to the possible questions that will be asked.

The questions a research proposal must answer, are: (i) Why should anyone be interested in my research? (ii) Is the research design credible, achievable and carefully explained - in other words, is it logical? (iii) Is the researcher capable of doing the research? (Bottorff, 2002:7). Silverman (2000:113-117) suggests that the researcher (whether qualitative or quantitative) answers these questions properly. This can be achieved by focusing on the following guidelines: be practical, be persuasive, make broader links, aim for crystal clarity and plan before you write.

\section{Be practical}

Indicate to the members of the proposal evaluation committee or funding agency reviewers how your research will address the identified research problem or solve an issue, for example, staff morale or patients' perceptions of quality of care. Research that concerns practical problems cannot be shrugged off even if the researcher is proposing to do a purely academic piece of research with no expectation that it will be read outside the university community (Silverman. 2000:114). The audience is therefore very important when preparing the proposal. Strauss and Corbin (1990:237-239) differentiate between four types of audiences and their different expectations, namely academic colleagues, policy-makers, practitioners and lay audiences. For proposal acceptance the audience will be the members of the proposal evaluation committee or/and the funding agency reviewers.

The University of Jyväskylä provides guidelines to their post graduate students and indicate that they should distinguish between the following audiences (http://www.jyu.fi/hum/ laitokset/kielet/oppiaineet_kls/ englanti/research/postgrad/ instructions, accessed 31/07/2008):

(i) the research community that it addresses (i.e. those doing research on similar or related questions); and / or (ii) to a community of practitioners who work with the kinds of problems or questions that your study addresses (e.g. language teachers, text producers, professionals who design language / communication training, etc.); and /or (iii) to the broader social community or society as a whole (e.g. does your research address questions that are important for particular groups of people or questions which are currently debated in society?)

\section{Be persuasive}

Morse (1994:226) explains that "the first principle of grantmanship (and for that matter approval of your proposal) is to recognize that a good proposal is an argument ... the proposal must take a case to the proposal evaluation committee or funding agency that the research question is interesting and that the study is important. Thus the proposal must be written persuasively." As a researcher you must be balanced, with a realistic understanding of what you can achieve (Silverman, 2000: 114). To be persuasive implies that "you must convince other people, like other researchers, research funding agencies, educational institutions, and supervisors that your research is worth spending scarce resources on. You convince people of the value of your work by showing them how your research will make a difference to the world, or by identifying a dilemma in existing theory which your research will help resolve" (Higson-Smith, Parle, Lange \& Tothill, 2000:5). 


\section{Make broader links}

The researcher should demonstrate in the proposal the understanding of the broader implications of the proposed research (Silverman, 2000:114-115). Morse (1994:227) suggests that one way of achieving this is to "place the problem in context to show, for instance, that when we understand this, we will be able to work on that". For example, indicate how your research will improve practice or influence policy.

\section{Aim for crystal clarity}

The aim of the researcher should be for clearly stated, in simple language that describes the research in a way that non-specialists can comprehend. Morse (1994:227) argues that the researcher should resist the temptation to lapse into pure jargon, as "some of the reviewers will be from other disciplines, and the proposal writer should assume nothing and explain everything". Silverman (2000:115) gives advice to the researcher and states that the proposal should be concise, using short, simple sentences.

\section{Plan before you write}

Remember the saying "If you fail to plan, you plan to fail." It is important that the writer plans the process, as the proposal should not only demonstrate that it is based on an intelligent understanding of the existing literature, but it must also show that the writer has thought about the time needed to conduct each stage of the research (Silverman, 2000:116). Time management is embedded in the planning process. The proposal will also be judged on the researcher's account of how time will be used. Arber (1993:35) notes that one needs "to adopt a systematic and logical approach to research, the key to which is the planning and management of your time". Attention is given to timelines further on in the manuscript.

\section{Structure of the \\ qualitative proposal}

The key sections of a qualitative proposal are listed below and attention will be paid to each. As explained above, this framework is meant to guide the qualitative researcher, but is not intended to be used as a recipe. The framework should be applied within the uniqueness of each study.

\section{Cover page}

Formal documents usually have a cover page. The format of the cover page is often provided by the proposal evaluation committee or the funding agency. If no format is provided, create a cover page and include the following (Morse \& Field, 1996:39-40):

- Title of the proposal.

- Name and affiliation of the researcher (principal investigator) and add coinvestigators (if relevant). The affiliation will include the type of degree, for example Master in Public

Administration, as well as the name of the university where the study will be conducted.

- Lines for the signatures of the researcher as well as the university authorities.

- Contact detail informationaddress, phone and fax numbers, and e-mail address.

\section{Abstract}

The abstract is a synopsis of the proposal; yet it is important that it is comprehensive enough to inform the evaluators or reviewers, and to introduce the project (Morse \& Field, 1996:40). It should include a short introduction to the research problem, the research question, research purpose and objectives, followed by the research design and research method. The abstract is usually 250 300 words long, but this is often dictated by the committee guidelines or the funding agency. First impressions count, and this is also true for the abstract, as this will be the first part that the reviewers read. It is advisable to leave the writing of the abstract until the end, as it will be easier to write after you have clarity of the research process. The inclusion of no more than five keywords is advisable at the end of the abstract. Structure can be given to the abstract by adding headings, i.e. Background, Aim (Purpose and specific objectives), Data Source, Method, Results and Conclusion, followed by Keywords.

\section{Introduction}

Begin with something interesting that immediately catches attention. Introduce the question and what it is that you want to know or understand, and explain the interest in the topic (Heath, 1997:1). The introduction must get the attention of the reader and convince him/her of the value of the study, or, as Sandelowski (2002:9) describes it, it must "set the stage". At the beginning of the proposal the significance of the study should be stated and it must be made clear why there is a need for the study (Sandelowski, 2002:9). Burns and Grove (2005:667-668) provide questions that can be used to assess the significance of the study: (i) Who has an interest in the domain of inquiry? (ii) What do we already know about the topic? (iii) What has not been answered adequately in previous research and practice? And (iv) How will this research add to knowledge, practice, and policy in this area? Furthermore, the introduction sets the scene and puts the research in context (Burnard, 2004:175). When writing for an international audience, it is important to place the research in an international context.

\section{Review of the literature}

Relevant literature should be cited that demonstrates the need for the research study in such a manner that it convinces the evaluators or reviewers that the study is worthwhile. "Literature consists of all written sources relevant to the topic you have selected" [or the phenomenon under investigation] (Burns \& Grove, 2005:93). It is often a challenge to include all relevant or most supportive literature as data, knowledge and information availability expand daily in the digitally enhanced knowledge environment, doubling every eighteen months in 2008 . It is therefore suggested that the researcher critique previous research, and demonstrates how the present study will clarify or compensate for shortcomings in previous research and how the study will add to the existing body of knowledge. The literature review provides a theoretical context for the study, but is not a conceptual framework, as it does not drive the study or provide an outline for the analysis (Morse \& Field, 1996: 41). Apart from simply offering an account of the research that has been carried out previously, the author should 
describe how' he or she searched the literature. This involves describing the computer search engines used and the keywords entered into those engines (Burnard. 2004:175). For example: "Searches were performed using the following resources: Nexus database, South African journal database or SAePublications, international journal databases (EBSCOhost and ScienceDirect), books, dictionaries, theses and dissertations from the North-West University library and inter-library loans" (Knobloch \& Klopper, 2008:6).

The literature review is not necessarily a separate heading, as it could be integrated in the introduction, providing a rationale for the planned study. Burns \& Grove (2005:95) point out that the purpose and the timing of the literature review could vary in qualitative research, based on the type of study to be conducted. Table 1 summarises the purpose of the literature review in qualitative research.

\section{Research problem (and research question)}

In this section the researcher answers the question: "What is the problem?" Sandelowski (2002:9) suggests that numbers should be used to document the extent and nature of the problem. As research is a logical process, the

\section{Table 1. Purposes of the literature review in qualitative research (Burns \& Grove, 2005:95).}

\begin{tabular}{|l|l|}
\hline Type of qualitative research & Purpose of the literature review \\
\hline Phenomenological research & $\begin{array}{l}\text { Compare and combine findings from } \\
\text { the study with the literature to } \\
\text { determine current knowledge of a } \\
\text { phenomenon }\end{array}$ \\
\hline Grounded theory research & $\begin{array}{l}\text { Use the literature to explain, support, } \\
\text { and extend the theory generated in the } \\
\text { study }\end{array}$ \\
\hline Ethnographical research & $\begin{array}{l}\text { Review the literature to provide a } \\
\text { background for conducting the study, } \\
\text { as in quantitative research }\end{array}$ \\
\hline Historical research & $\begin{array}{l}\text { Literature is reviewed to develop } \\
\text { research questions and is a source of } \\
\text { data }\end{array}$ \\
\hline
\end{tabular}

research problem is a synthesis of the introduction and literature review; in other words, it is a "diagnosis" of the problem. The problem can be broad, but must be specific enough to convince the reviewers that it is worth focusing on (Bottorff, 2002:11). The section on the research problem must conclude with the research question to be answered. The research question(s) should be how questions. The following format is suggested to structure research questions for qualitative studies (but it is also relevant to quantitative studies) (http:// filebox.vt.edu/users/nespor/design. accessed 17 May 2004):

- How has/have the activity/ relations changed as the activity/relations has/have changed? "Activities" refer to relatively long-term, ongoing, collective social endeavours (for example studying at university, living a healthy lifestyle, raising a family, etc.). "Relations" refer to on-going systems of relations organised around gender, ethnic group, age, or between the role players in a formal organisation, for example worker/supervisor; student/lecturer; health care professional/patient. Example: How has health service delivery changed as health policy changed?

- How do concrete actors make sense of /respond to / accomplish the activity/ policy that play a key role in their lives? "Concrete actors" are historically and geographically situated people, organisations, and institutions.

Example: How do primary care workers respond to shortages of personnel in rural clinics?

- How is the artefact /tool/ policy used by concrete actors? "Artefacts, tools, and policies" are used in more or less their everyday meanings, although "tools and artefacts" should be thought of as encompassing technologies

Example: How is the primary health care policy implemented by different health professions?

What happens to the system of relations when the activity, takes place?

Example: What happens to the quality of care of patients from a low income status if they cannot access health care?

In summary, the research questions clearly delineate the research (sometimes with sub-questions), and the scope of the research questions(s) needs to be manageable within the time frame and context of the study (Bottorff, 2002:11).

\section{Research purpose and objectives}

The research purpose (or goal, or aim) gives a broad indication of what the researcher wishes to achieve in the research. The research purpose is a concise, clear statement of the specific goal of the study (Bums \& Grove, 2005: $71)$. The purpose usually indicates the type of study to be conducted, i.e. identify, describe, explain, or predict. Mouton and Marais (1994:51; also compare Mouton, 1996:103) presents a classification of different types of research studies to present "a more systematic picture of different kinds of 


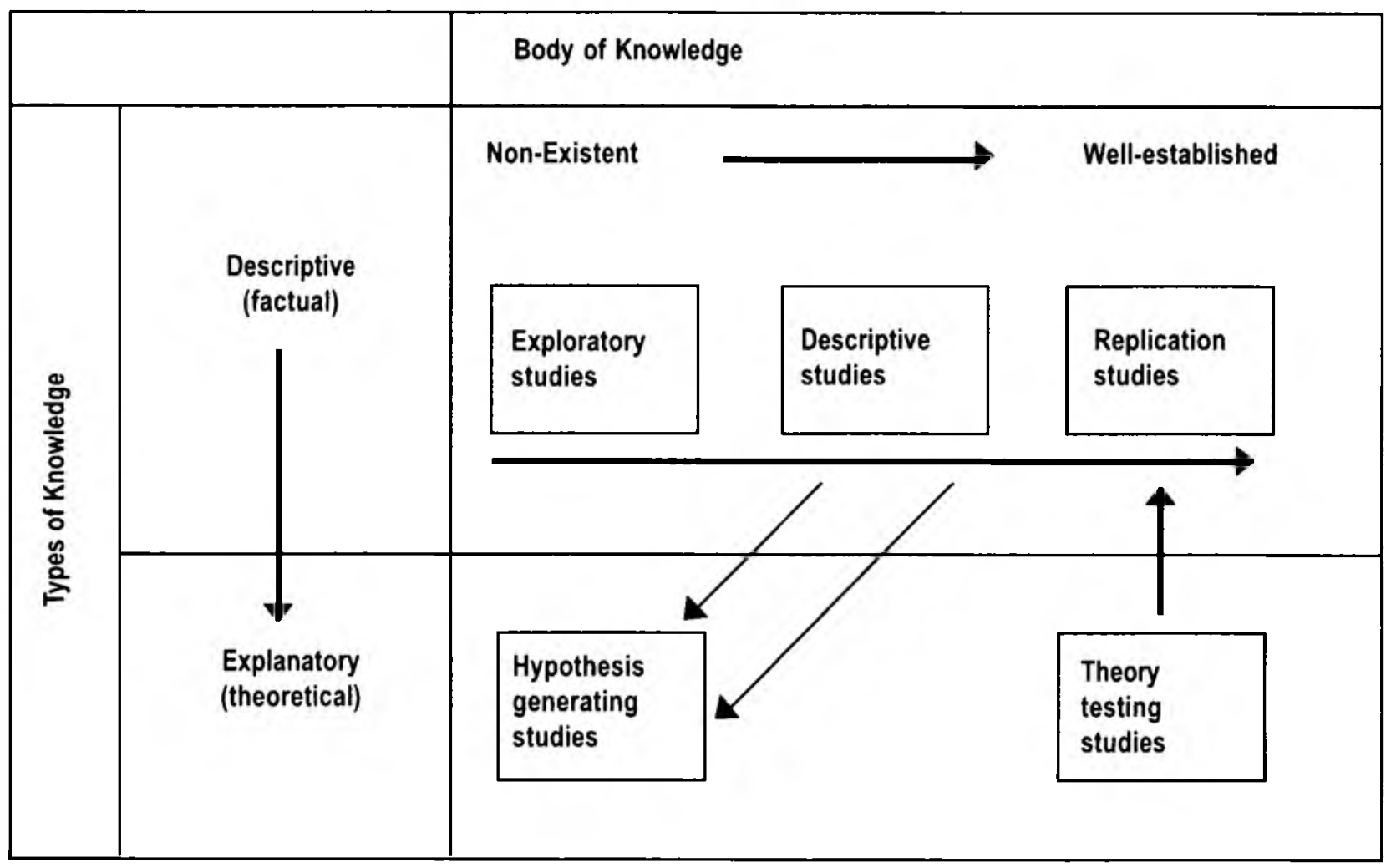

research objectives". However, he suggests that there are more basic questions to consider, before attention is given to the classification, i.e. "What are the factors that come into play when a researcher identifies a particular research purpose? What makes a researcher opt for a descriptive purpose rather than an explanatory purpose? Which factors play a role in determining a choice for or against evaluating health care interventions?" Mouton (1996:102) further argues that over and above the questions, there are factors that determine the clarification of the research purpose, such as "the researchers' existing background knowledge (epistemic dimension) of the particular phenomenon and the interests, motives and preferences of the researcher (the sociological dimension)".

The epistemic dimension focuses on existing knowledge. Mouton (1996:102103) differentiates between two types of existing knowledge, i.e. descriptive (or factual) and explanatory (or theoretical) knowledge. Descriptive knowledge includes data, facts, empirical generalisations, narratives and stories, and provides truthful descriptions of phenomena. "Descriptive statements make claims about how things are, and what the actual fact of the matter is" (Mouton, 1996: 192). Explanatory knowledge includes models, theories, interpretations, and makes causal claims about the world. "Explanatory statements suggest plausible explanations of why things are as they are, and what the causes of events behind change are (Mouton, 1996:192193). Mouton (1996:193) further points out that the existence of a wellestablished body of knowledge versus little known about a phenomenon, will also impact on the choice of purpose. If little or no previous research is known about the phenomenon under investigation, a different kind of research would be appropriate in comparison with a phenomenon for which there is an existence of a wellestablished body of knowledge. In the first case, the researcher will attempt to collect new data through an exploratory study. In the latter case, new studies will possibly focus on validational or confirmatory studies.
The typology in figure I illustrates how the types of knowledge and the nonexistence or existence of a body of knowledge will influence the researcher's choice of study.

The second dimension discussed by Mouton (1996:41-45) is the sociological dimension, i.e. research as social activity. This implies that: (i) The researchers are social beings with specific beliefs, values and interests; (ii) Researchers follow certain implicit and explicit rules; (iii) The activities of researchers are conducted within more or less organised and institutionalised frameworks, which impose certain constraints on what is acceptable; and (iv) Researchers stand in different relations of power to each other (Mouton, 1996:41). What is important for the purpose of our discussion is that the researcher should be aware of his/her motives and intentions.

In summary, the research purpose is logically (deduced) generated from the research problem, it identifies the purpose of the study, and directs the development of the study (Burns \& Grove 2005:80). Based on the research 
purpose, specific research objectives are developed to direct the study. The following is an example of the research aim (purpose) and objectives from a study conducted by Minnie (2007; Minnie, Klopper \& Van der Walt, 2008:51): "The aim of this research is to develop best practice guidelines for counselling for HIV testing during pregnancy. This aim is achieved by means of the following objectives:

- To explore and describe the factors that influence pregnant women's decision to be tested for HIV in selected antenatal clinics in the North West Province;

- To explore and describe the factors that influence the counselling for HIV testing during pregnancy according to counsellors who practice in selected antenatal clinics in the North West Province;

- To describe the current practices regarding counselling for HIV testing during pregnancy in selected clinics in the North West Province; and

- $\quad$ To describe the evidence regarding counselling for HIV testing during pregnancy by means of systematic review.

\section{Research paradigm}

No research is value free. "All studies include assumptions about the world and knowledge that informs the inquiries" (Creswell \& Plano Clark, $2007: 20$ ). It is therefore advisable that you include an explicit stance of your paradigm (often referred to by authors as a worldview) in the proposal especially when you expect to have reviewers who are not familiar with qualitative research. All researchers bring a paradigm(s) or worldview to their research and this will influence the design and conducting of the research. "Worldviews and paradigms mean how we view the world and, thus, go about conducting research" (Creswell \& Plano Clark, 2007:21). Guba and Lincoln (2005:192) state that the paradigm contains a basic set of beliefs and assumptions that guide our inquiries. Heath (1997:1-2) makes useful suggestions on the description of the paradigm:
- Use specific language to name and describe your research paradigm, e.g. "naturalistic", "poststructuralism".

- Describe the philosophical correlates of your research paradigm, e.g. phenomenology, hermeneutics.

- $\quad$ Cite authors who have defined your research paradigm in the health sciences and suggested its application to your field of study and/or your specific area of study.

The message is clear - explain the assumptions of your research paradigm. The paradigm or paradigmatic perspective includes meta-theoretical, theoretical and methodological assumptions. Metatheoretical assumptions (statements) refer to the researcher's beliefs about the human being (patient, health care professional), society (community), the discipline (nursing, medicine, physiotherapy), and the purpose of the discipline (health). These assumptions are often embedded in paradigms or worldviews, i.e. Positivism, Postpositivism, Critical Theory, and Constructivism. Meta-theoretical statements are axiomatic statements and are not meant to be tested. The following excerpt is an example of a paradigmatic statement from a study by Maphorisa, Poggenpoel and Myburgh (2002:23): "The researcher will incorporate the Theory for Health Promotion in Nursing (RAU, 1999) as paradigmatic perspective for this research. It endorses a Christian perspective. The following parameters of Nursing are also identified: community mental health nurse, mental health, environment and mental health nursing". The authors then continue to provide clarifications of the four listed parameters by defining them from a faith perspective.

Theoretical assumptions or statements are a reflection of the researcher's view of valid knowledge in existing theoretical or conceptual frameworks. The theoretical statements are epistemic in nature and are subject to testing with the intention of clarifying the research problem. Theoretical assumptions are theoretical statements that serve as a framework in the study, and include theories, models and concepts (theoretical and operational definitions).

To demonstrate the different approaches in qualitative studies, two examples are given. In the first example the researcher approaches the research field with no preconceived framework; and in second example, definitions are provided, i.e. the researcher is departing from a specific framework. Example one comes from a study conducted by Maphorisa et al. (2002:25): "A literature control will be conducted after the phenomenological interview's have been analysed; thus the researcher will approach the field with no preconceived framework of reference." The second example is from a study conducted by Minnaar (2001:20): "The framework that was used for this study was the Caring Theory of Watson. Watson (1985) identified ten curative factors which encourage health and development of individuals, families and communities. The ten carative factors are the formation of a humanaltruistic system of values; the installation of hope and faith; the cultivation of sensitivity to oneself and to others; the development of a helping-trust relationship between the caregiver and the care receiver to ensure a relationship of quality; the promotion and acceptance of the expression of positive and negative feelings".

Methodological assumptions or statements explain what the researcher believes good science practice is and may be implied or explicitly stated. An example from a study in which the methodological assumptions are stated explicitly is given below (Maphorisa et al 2002:23): "The methodological assumptions, which will guide this study, are in line with the Botes Model of Research (1998). The assumptions are based on the functional approach that implies that research must be applicable to improve the practice. The usefulness of the research in itself provides its trustworthiness."

\section{Research design}

Research starts with a problem and is a 
Table 2. Typology of research designs (adapted from Mouton and Marais 1996)

\begin{tabular}{|c|c|c|c|}
\hline \multirow[t]{2}{*}{$\begin{array}{l}\text { GENERAL INTEREST } \\
\text { (Universal or Nomothetic) }\end{array}$} & $\begin{array}{l}\text { Research goal } \\
\text { Explanatory }\end{array}$ & $\begin{array}{l}\text { Collection of new data } \\
\text { Experimental and } \\
\text { Quasi-experimental designs }\end{array}$ & Analysis of existing data \\
\hline & \begin{tabular}{|l} 
Descriptive \\
Exploratory
\end{tabular} & $\begin{array}{l}\text { Survey designs } \\
\text { (Questionnaires, interviews } \\
\text { and indirect observation) } \\
\text { Survey designs(Pilot studies) }\end{array}$ & $\begin{array}{l}\text { Secondary analysis } \\
\text { (Census data) } \\
\text { Quantitative content analysis } \\
\text { (Newspaper reports, } \\
\text { speeches, etc) }\end{array}$ \\
\hline \multirow[t]{3}{*}{$\begin{array}{l}\text { CONTEXTUALINTEREST } \\
\text { (Contextual or ideographic) }\end{array}$} & Explanatory(Verstehen) & $\begin{array}{l}\text { Grounded theory } \\
\text { Theory development }\end{array}$ & $\begin{array}{l}\text { Qualitative content analysis } \\
\text { Discourse analysis } \\
\text { Historical analysis } \\
\text { (What was the cause of } X \text { ?) }\end{array}$ \\
\hline & Descriptive & $\begin{array}{l}\text { Field designs or } \\
\text { Ethnographic designs (with } \\
\text { the focus on unstructured } \\
\text { direct and indirect } \\
\text { observations) } \\
\text { E.g. Case study } \\
\text { Model development } \\
\text { Narrative Inquiry } \\
\text { Critical ethnography }\end{array}$ & $\begin{array}{l}\text { Qualitative content analysis } \\
\text { Discourse analysis } \\
\text { Historical analysis } \\
\text { (What happened?) }\end{array}$ \\
\hline & Exploratory & $\begin{array}{l}\text { Field designs or } \\
\text { Ethnographic designs (with } \\
\text { the emphasis on the use of } \\
\text { informants) } \\
\text { E.g. Autoethnography } \\
\text { Ethnography }\end{array}$ & \\
\hline
\end{tabular}

precondition for any study. The development of a research design follows logically from the research problem. This implies that the research problem directs the choice of design. A research design is defined as "a set of guidelines and instructions to be followed in addressing the research problem" (Mouton, 1996:107). Mouton further suggests that the main function of a research design is to enable the researcher to anticipate what the appropriate research decisions should be in such a manner that the eventual validity of the research findings are maximised. The research design is the plan or blueprint that the researcher will use in conducting the research. The aim of the research design is to align the pursuit of a research goal with the practical considerations and limitations of the project (Mouton \& Marais, 1994:32). The following components are usually addressed in the design: its qualitative or quantitative (or mixed) nature; whether the study is explorative, descriptive, comparative or explanatory; and whether the study is contextual or universal. Qualitative studies are always contextual, as the data is only valid in a specific context. The researcher can then follow with a short description of each component. In the description of a contextual study it is important to include a description of the context or setting in which the research will be conducted. Also explain why this setting was chosen. Mouton and Marais (1994:51) provide a typology of research designs which, although not exhaustive, may be used as a guide (refer to Table 2).

The following is an example of a research design (Maphorisa et al 2002:24): "The design of this study is qualitative, explorative, descriptive and contextual in nature. Its qualitativeness offers the opportunity to uncover the nature of the community mental health nurses' actions, experiences and perspectives of which is little known as yet. The purpose of its exploration is to gain a richer understanding of the experiences. According to Burns and Grove (2001), a descriptive study is usually conducted when little is known about the phenomenon of interest. Mouton (1996) describes a contextual study 
as one in which the phenomenon under investigation is studied in terms of its intrinsic and immediate contextual significance."

\section{Research method}

The research design will influence your decisions about research methods. Researchers give different interpretations as to what the research method refers to. In this article research method includes the steps of population and sample, data collection, ensuring rigor and data analysis. Each of the steps will be discussed.

\section{- $\quad$ Population and sample}

"Population refers to all the elements (individuals, objects or substances) that meet certain criteria for inclusion in a given universe" (Burns \& Grove, 2005:40). They further indicate that the definition of the population depends on the sample criteria and the similarity of participants in the various settings. Describe the composition of the population (N) in your study. Explain how you will select participants and gain entry into the research context (if relevant) (Heath, 1997). Then continue with a description of the sample, and sampling technique. A sample is a subset of the population that is selected for a particular study. Name the sampling technique you will use and defend its use, for example motivate why you would use purposive sampling. State the inclusion and exclusion criteria, and lastly project the size of the sample (n). An example from a study by Mchunu and Gwele (2005: 33) is given: "The population consisted of community health centres, health professionals in these centres, and the surrounding communities, in the different community settings in the Ethekweni health district".

\section{- Data collection}

The researcher describes what he/she is aiming to find out and how the data will be collected. The process of description will depend on the researcher's use of an inductive or deductive strategy, as this will influence the decision of whether the qualitative research will be carried out departing from a theoretical framework or not. With an inductive strategy the researcher would embark upon the project without working from an explicit conceptual framework, and merely use a central theoretical statement to guide the research. In the deductive strategy the researcher embarks upon a research project with a clear conceptual framework in mind. This may be a model, a theory, or a typology. The use of a deductive strategy leads to a relatively rigid manner of conceptualisation, operationalisation, and data collection, and will ultimately constitute the frame of reference for analysis and interpretation (also compare Mouton, 1996:80).

It is important that the researcher describes the kind of data that will be collected, e.g. examination of existing documents, field notes, audiotapes, focus groups, videos, internet-based data, etc); and how data will be collected e.g. interviews, discourse analysis, etc. The method must be described in detail, as it will become part of the audit trail (Heath, 1997:2). Agar (1980, in Morse \& Field, 1996:42) notes that it is inadequate to simply refer to data that will be collected using "participant observation, field notes or diaries". A description with the justification of each method and how the method contributes to the understanding of the phenomenon under study must be presented. If an interview guide will be used, include the questions in the proposal or attach as an appendix. Explain in detail how interviews will be conducted, i.e. include how focus groups will be conducted, inclusive of the role of the facilitator and moderator, and how responses to questions will be elicited (Sandelowski, 2002:17). An example from Morolong and Chabeli (2005: 42) is given: "Observation and questioning were preferable data collection methods. For the main study, the researcher was assisted by an experienced expert clinical accompanist who was purposively selected for data collection. The researcher and the assistant used the developed instrument and its related manual, to evaluate the competence of newly qualified registered nurses".

\section{- $\quad$ Rigor (Soundness of the research)}

Rigor must be reflected throughout the proposal. However, it is vital that the researcher addresses rigor specifically, using relevant criteria and appropriate strategies for the qualitative design used. Lincoln and Guba (1985:218) propose an alternative construct for validity and reliability in qualitative research, namely trustworthiness. The epistemological standards of trustworthiness are:

\section{(i) Truth value}

Truth value determines whether the researcher has established confidence in the truth of the findings with the participants and the context in which the research was undertaken. Truth value is usually obtained from the discovery of human experiences as they are lived and perceived by the participants (Klopper \& Knobloch, 2008a:5, Sliep, Poggenpoel \& Gmeiner, 2001:69). Truth value is obtained by using the strategy of credibility and the criteria of prolonged engagement, triangulation (of methods, data sources, theories and investigators), peerexamination/group discussion, negative case analysis and member checking.

\section{(ii) Applicability}

Applicability refers to the degree to which the findings can be applied to different contexts and groups (Sliep et al. 2001:69). It is the ability to generalise from the findings to larger populations, by using the strategy of transferability (Klopper \& Knobloch, 2008a:8).

\section{(iii) Consistency}

Consistency considers whether the findings will be consistent if the inquiry was replicated with the same participants and in a similar context. Since the qualitative setting may be complicated by extraneous and an unexpected variable, the strategy of dependability is used, which implies traceable variability; this is variability that can be ascribed to identifiable sources (Sliep et al. 2001:69-70). To ensure consistency Guba and Lincoln (1985:298-299) discuss direct and indirect ways with which the dependability of research findings may be ensured. Dependability may be ensured in an indirect way by applying the measures of credibility. The three direct ways that the dependability of research findings may be ensured are: stepwise replication (inclusive of a thick or dense description of the methodology), inquiry audit (sometimes referred to as the dependability audit) and triangulation (Klopper \& Knobloch, 2008a: 10).

(iv) Neutrality 
Table 3. Summary of standards, strategies and criteria to ensure trustworthiness

\begin{tabular}{|c|c|c|c|}
\hline Epistemological standards & Strategies & \multicolumn{2}{|l|}{ Criteria } \\
\hline Truth value & $\begin{array}{c}\text { Credibility } \\
\\
\\
.\end{array}$ & $\begin{array}{ll}\text { - } & \mathrm{Pr} \\
\text { - } & \mathrm{Tr}_{\mathrm{r}} \\
& \text { • } \\
\text { - } & \mathrm{Pe} \\
\text { - } & \mathrm{N} \\
\text { - } & \mathrm{M}\end{array}$ & $\begin{array}{l}\text { ged engagement } \\
\text { dlation } \\
\text { Methods } \\
\text { Participants } \\
\text { amination/group discussion } \\
\text { ve case analysis } \\
\text { er checking }\end{array}$ \\
\hline Applicability & Transferability & $\begin{array}{ll}- & \mathrm{Se} \\
\text { - } & \mathrm{Sa} \\
\text { - } & \mathrm{Tl}\end{array}$ & $\begin{array}{l}\text { on of sources } \\
\text { ion of Data } \\
\text { Description }\end{array}$ \\
\hline Consistency & Dependability & 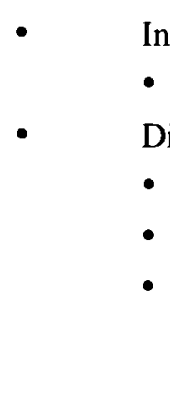 & $\begin{array}{l}\text { Measures of credibility } \\
\text { Stepwise replication } \\
\text { Inquiry audit } \\
\text { Triangulation } \\
\text { - Methods } \\
\text { - Participants }\end{array}$ \\
\hline & Confirmability & $\begin{array}{ll}\cdot & \mathrm{C} \\
\cdot & \mathrm{Tr} \\
& \bullet \\
& \bullet\end{array}$ & $\begin{array}{l}\text { nability audit } \\
\text { dlation } \\
\text { Methods } \\
\text { Participants }\end{array}$ \\
\hline
\end{tabular}

Neutrality entails freedom from bias during the research process and results description, and refers to the degree to which the findings are a function solely of the informants and conditions of the research, and not of other biases, motives or perspectives (Sliep et al. 2001:70). The strategy of confirmability is used, and the criteria of the confirmability audit and triangulation are applied (Klopper \& Knobloch, 2008a:12).

The term trustworthiness is therefore used in the evaluation of the rigor of qualitative data. Table 3 provides a summary of the epistemological standards, the strategies and criteria used to ensure trustworthiness in qualitative research.

\section{- Data analysis}

Describe the intended data analysis procedure (coding, sorting, etc.). The researcher needs to give a description of how data reduction and data reconstruction is planned, as well as how data will be kept organised and retrievable. In explaining data reduction the researcher provides detail of write-ups of field notes, transcription procedures and the use of computer programmes (if planned) (Heath, 1997:3). Data reconstruction includes a description of the development of themes, control with existing literature and integration of concepts (Heath, 1997:3). For the description of data analysis, relevant methods with citations must be included, e.g. content analysis (Tesch, 1990 in Creswell 1994:155); qualitative content analysis (Altheide, 1987:65-67); constant comparison analysis (Strauss and Corbin 1990:62); and phenomenological thematic analysis (Van Maanen, 1990:3) (compare
Sandelowski, 2002; Sandelowski \& Barroso, 2003). The use of computer programmes to conduct data analysis, i.e. Atlas ti or Nvivo 8 should also be clearly indicated. The study of Maphorisa et al. (2002:24) is used as example:

"The method of data analysis of Tesch in Creswell (1994) was used to analyse the tape recorded data after transcription. During the data analysis, all the transcriptions were read to get a sense of the whole. Ideas were jotted in the margin as they came to mind. A list of all topics from all the interviews was made and similar topics were clustered together These topics were formed into major topics, unique topics and leftovers. They were later taken and returned to the data and abbreviated as codes. These codes were written next to the appropriate segments of the text ..". 


\section{Ethical considerations}

Qualitative research introduces special moral and ethical problems that are not usually encountered by other researchers during data collection; perhaps due to the unstructured conversational tone of interviews and the intimate nature of the interaction between the researcher and participants (Morse \& Field, 1996:44). It is therefore very important that the researcher take special care in ensuring that ethical standards are met. Ethical considerations refer to the protection of the participants' rights, obtaining informed consent and the institutional review process (ethical approval). The researcher needs to provide adequate information on each of these aspects. Protection of participants' rights include the right to self-determination, right to privacy, right to autonomy and confidentiality, right to fair treatment and the right to protection from discomfort and harm. Informed consent needs to be obtained from the participants, as well as the research site and the relevant authorities.

\section{Dissemination plan}

The researcher should provide a condensed description of the plan that will be utilised to disseminate results, i.e. publication in peer-reviewed journals and paper or poster presentations at conferences. Also take into consideration specific requirements for dissemination for postgraduate studies, or funding agencies.

\section{Timeline}

The timeline is a schedule or work plan for the completion of the research (Morse \& Field, 1996:42-43). The plan includes all the research activities to be completed, the predicted length of time that each activity will take to complete and when it will be performed. The plan can be described as text, but as several tasks may be conducted concurrently, it is often presented as a table or graph. A possibility is the use of the Gantt chart. A Gantt chart is a standard tool that can be used by the researcher to structure the timeline of the project, i.e. specific activities with target dates. Qualitative researchers are often very optimistic about the time to be allowed for the research activities, but the qualitative researcher can experience numerous delays, for instance; delays with interviews and the time-consuming process of qualitative data analysis. Morse and Field (1996:43) advise that the researcher should estimate how long each activity will take and then triple the time. Such leeway is important when funds are requested, to ensure that there is adequate funding for staff and for the completion of the project.

\section{Budget}

A notion which interferes with the positive perception of qualitative inquiry is the idea that qualitative research is inexpensive to conduct (Morse, 2003:847). This is a myth. Qualitative research is not predictable; hence when the researcher prepares a research budget, he/she should predict and cost all aspects of the research, and then add an additional allowance for unpredictable disasters, delays and rising costs. Morse and Field (1996:43) refer to specific aspects that should be included in the budget: the number of participations cannot be predicted, because data will be collected until saturation, but an estimation must be included; recording of data (audiotapes, recorder, batteries, microphone); transcripts of interviews (on average, a fast typist will need three hours to transcribe a clearly recorded 45-minute interview); equipment (make, model number and actual price); personnel budget (include employee benefits); supplies (telephone, stationary); travel; cost of attending a conference for dissemination. All items in the budget should be justified.

\section{Appendices}

Appendices are documents that support the proposal and application. The appendices will be specific for each proposal, but documents that are usually required include: informed consent form; telephone consent; verification of ethical approval; letters of approval from research site; letters of support (in case of funding application); curricula vitae of researcher (principal investigator) and others members of the research team.

\section{Conclusion}

In summary, successful qualitative research proposals should communicate the researcher's knowledge of the field and method, and convey the emergent nature of the qualitative design. The proposal should follow a discernible logic from the introduction to presentation of the appendices. Successful qualitative research proposals are an art and science (Sandelowski, 2002:20) and should be written to entice the audience and to conform to the requirements of the funding agency (Morse \& Field, 1996:141-142).

\section{Acknowledgement}

Thanks to Siedine Knobloch (project manager in my office) for the final proof reading and assistance with the abstract.

\section{References}

AGAR, MH 1980: The Professional Stranger: An Informal Introduction to Ethnography. New York: Academic Press

ALTHEIDE, DL 1987: Ethnographic content analysis. Qualitative Sociology. 10:65-67.

ARBER, S 1993: The Research Process. (In: Gilbert, N. Researching Social Life). London: Sage.

BELGRAVE, LL\& SMITH, KJ 1995: Negotiated validity in collaborative ethnography. Oualitative Inquiry, 1:6989

BOTTORFF, JL 2002: Writing Qualitative Research Proposals. Retrieved 17 May 2004 from www.vchri.ca/i/ presentations/ qualitative proposals.

BURNARD, P 2004: Writing a qualitative research report Nurse Education Today. 24 (3): 174-179

BURNS, N \& GROVE, SK 2005: The Practice of Nursing Research. Conduct, Critique and Utilization. London: Elsevier Saunders Company

CRESWELL, J 1994: Research design: Qualitative and quantitative approaches. London: Sage

CRESWELL,JW \& PLANO CLARK, VL, 2007: Designing and conducting Mixed Method Research. USA: Sage Publications

DENZIN, NK \& LINCOLN, YS 1998: 
Strategies of Qualitative Inquiry. Thousand Oaks, CA: Sage

HEATH, AW 1997: The proposal in Qualitative Research. The Qualitative Report. 3 (1). Retrieved on 17 May 2004 from www.nova.edu/ssss/OR/OR3-1/ heath.html.

HIGSON-SMITH, C; PARLE, J; LANGE, L \& TOTHILL, A 2000: Writing your research proposal. A workbook for first time and inexperienced researchers in the Social Sciences and Humanities. NRF: South Africa; online from http:// www.nrf.ac.za/methods/proposals.htm

JONES, R 1995: Editorials: Why do qualitative research? British Medical Journal. Volume 311:2(1 July).

KLOPPER, HC 1995: Vertrouenswaardigheidstrategieë (Trustworthiness Strategies) RAUCUR. 1 (1): 25-28

KLOPPER, HC \& KNOBLOCH, S 2008: Validity, reliability, and trustworthiness (Submitted manuscript) pp.1-18

KNOBLOCH, S \& KLOPPER, HC. 2008: Compassion fatigue within the nursing practice: A concept analysis (Submitted for publication).

LINCOLN, YS \& GUBA, EG 1985: Naturalistic Inquiry. London: Sage

LOISElle, CG, PROFETTOMCGRATH, J, POLIT, DF \& BECK, CT 2004: Canadian Essentials of Nursing Research. Philadelphia, USA: Lippincott Williams \& Wilkins

MALTERUD, K 2001: Qualitative research: standards, challenges and guidelines Lancet. 358 (928): 483-489

MANNING, K 1997: Authenticity in constructivist inquiry: Methodological considerations without prescriptions. Oualitative Inquiry. 3:93-115.

MAPHORISA, MK, POGGENPOEL, M \& MYBURGH, CPH 2002:

Community mental health nurses' experience of decentralized and integrated psychiatric-mental health care services in the Southern mental health region of Botswana. Curationis. 25(2): $22-29$

MAYS, N \& POPE, C 2000: Quality in qualitative health research. London: BMJ

MCHUNU, GG \& GWELE, NS 2005: The meaning of community involvement in health: the perspective of primary health care communities. Curationis. 28 (2): 38-50.

MINNAAR, A 2001: Caring for the caregivers - a nursing management perspective. Curationis. 24 (3): 19-26

MINNIE, CS 2007: Best Practice Guidelines for Counselling for HIV testing during pregnancy. (PhD Thesis). Potchefstroom: North-West University

MINNIE, K, KLOPPER, HC \& VAN DER WALT, SJC 2008: Factors contributing to the decision by pregnant women to be tested for HIV. Health SA Gesondheid. 13 (4): 50-65

MOROLONG, BG \& CHABELI, MM 2005: Competence of newly qualified registered nurses from a nursing college. Curationis. 28 (2): 38-50.

MORSE, JM 1994: Designing funded qualitative research. (In: Denzin, N \&Lincoln, YS (Eds) Handbook of Qualitative research). Thousand Oaks, CA: Sage

MORSE, JM, HUPCEY, J, PENROD, JA, SPIERS, J, POOLER C \& MITCHAM, C 2002: Issues of validity: Behavioral concepts, their derivation and interpretation. International Journal of Oualitative Methods, 1 (4) Article 3. Retrieved 20 May 2004 from http://www.ualberta.ca/ iigm.

MORSE, J 2003: A Review Committee's Guide for Evaluating Qualitative Proposals. Oualitative Health Research. 13 (6): 833-851

MOUTON, J 1996: Understanding Social Research. Pretoria: JL Van Schaik

MOUTON, J \& MARAIS, HC 1994: Basic Concepts in the methodology of Social Sciences. Pretoria: Human Sciences Research Council
RODGERS, BL \& COWLES, KV 1993: The qualitative research audit trial: A complex collection of documentation. Research in Nursing and Health. 16: 219-226.

SANDELOWSKI, M 2002: The Qualitative Research Proposal. U-M Conference on Qualitative Research Methods. Retrieved 13 May 2004 from www.umich.edu/ qualnet/material/ sandelowski.

SANDELOWSKI, M \& BARROSO,J 2003: Writing the Proposal for a Qualitative Research Methodology Project. Qualitative Health Research. 13(6): 781-820

SILVERMAN，D 2000: Doing Qualitative Research. A practical handbook. London: Sage

SLIEP, Y, POGGENPOEL, M \& GMEINER, AC 2001: A care counselling model for HIV reactive patients in rural Malawi. Curationis. 24 (3): 66-74

SMALING A 2002: The Argumentative Quality of the Qualitative Research Report. International Journal of Qualitative Methods. 1 (3): Article 4. Retrieved 22 May 2004 from http:// www.ualberta.ca ijqm

STRAUSS, A \& CORBIN, J 1990: Basics of qualitative research: Grounded theory procedure and techniques. Newbury Park, CA: Sage

UNIVERSITY OF JYVÄSKYLÄ (http: /www.jyu.fi/hum/laitokset/kielet/ oppiaineet_kls/ englanti/research/ postgrad/instructions, accessed 31 July 2008):

VAN MAANEN, M 1990: Researching lived experience: Human science for an action sensitive pedagogy. Albany: State University of New York Press 